\title{
One year's study of growth and total hydroxyproline excretion in scoliotic children
}

\author{
S CLARK, A HARRISON, AND P A ZORAB \\ Paediatric Department, Cardiothoracic Institute, London
}

SUMMARY 21 children with scoliosis were studied for a year during which time 24-hour urinary total hydroxyproline levels were estimated and anthropometric measurements were made on 4 occasions. The total hydroxyproline levels (using hydroxyproline centiles) and the uncorrected heights of the children were all normal. The sitting heights of the children were below average, but, although the sample was small, the findings indicate that the children's 'uncoiled' height would be greater than average.

In scoliosis, progressive changes in the vertebral column may occur with growth. Its onset is generally noticed in infancy or adolescence. ${ }^{1-2}$ Measurable deterioration can occur during times of rapid increase in height. Because of the curvature of the spine in scoliotic children, the predicted normal height for age and stage of development is difficult to estimate. Significant differences in standing height between normal and scoliotic children were found by Willner, ${ }^{3-4}$ and Burwell et al. ${ }^{5}$ Burwell and coworkers found disproportion in upper limb length which was related to the convexity of the curvature.

There is a close relationship between rate of growth and total hydroxyproline (THP) excretion. Fast growth rates are associated with high levels of urinary THP due to increased collagen turnover. ${ }^{6-9}$ Slow growth rates are associated with low THP levels. We studied THP excretion and anthropometric measurements of growth in a group of scoliotic children for a year. The purpose of the study was to compare the findings for these children with those for normal children ${ }^{10}$ to see if there was any difference in THP levels and body size between the two groups.

\section{Material}

21 children attending a scoliotic clinic as outpatients were studied. None of these children had had spinal surgery. 14 were girls with an age of 8 $2-16 \cdot 5$ (mean

\footnotetext{
Institute of Child Health, Alder Hey Children's Hospital, Liverpool

S CLARK, research associate

Department of Paediatrics, Cardiothoracic Institute

A HARRISON, research assistant

P A ZORAB, assistant director
}

age 12.6) years at their first attendance. Three of the boys were between 15 and 17 years, and 4 were between 8.75 and 10.5 years at the start of the study.

18 children were diagnosed as having idiopathic scoliosis: 6 girls and 3 boys had adolescent idiopathic scoliosis (AIS), 5 girls and 2 boys had juvenile idiopathic scoliosis (JIS), and 1 girl and 1 boy had infantile idiopathic scoliosis (IIS). Two girls had congenital scoliosis (hemivertebra present), and 1 boy had neurogenic scoliosis. ${ }^{11}$

The degree of spinal curvature ranged from 17 to $70^{\circ}$ (mean $47^{\circ}$ ). The children with AIS had curvatures between 40 and $70^{\circ}$ (mean $\left.54^{\circ}\right)$. The angulation was in the range 20 to $60^{\circ}$ (mean $39^{\circ}$ ) in children with JIS. The angulation was 43 and $54^{\circ}$ in the 2 children with IIS. 11 of the children each wore a Milwaukee brace, but the other 10 were not undergoing any form of treatment. The selection of patients was random within the above criteria.

\section{Methods}

Each child gave a 24-hour urine specimen every 3 months. These specimens were collected directly into wide-necked polyethylene containers, under parental supervision, and were always made on the day before visiting the outpatient clinic. The method of collection has been described in detail elsewhere. ${ }^{10} 12$ The children were on collagen-free diets. Each family was visited before the study began and given instructions for the urine collections; any problem concerning the diet, transport of specimens, etc., was discussed. Our previous experience in this field had shown the need for parental understanding and co-operation. 
The urine specimens were tested for THP levels and creatinine. Three specimens known to be incomplete were excluded from the study. The methods and criteria are described in an earlier paper. ${ }^{10}$ Anthropometric measurements (including uncorrected height) were made for each child, by the same person, at the outpatient clinic. Measurements were made on the left side of the body so that they could be compared with data for normal children. ${ }^{13}$

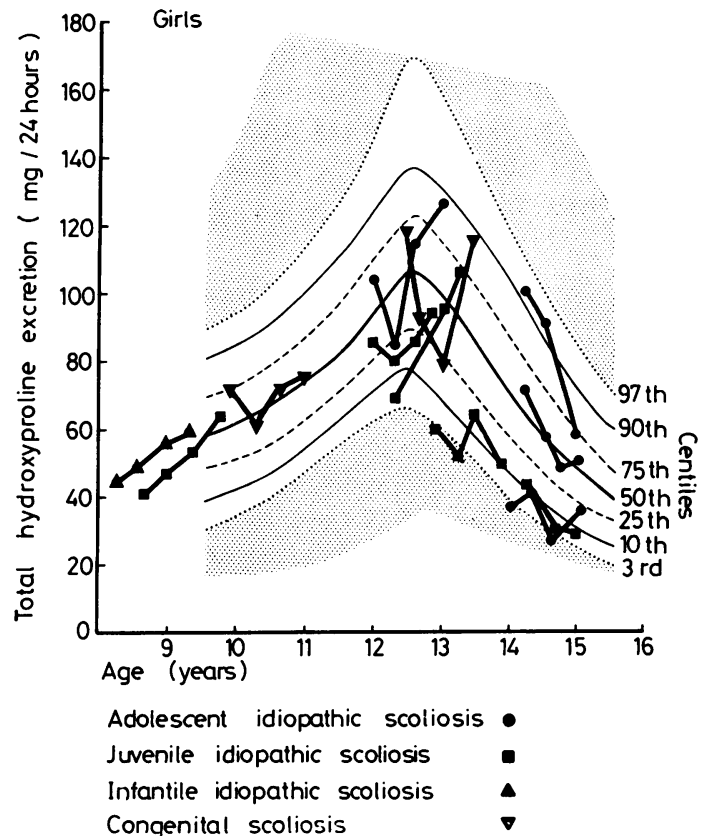

Fig. 1 Scoliotic girls: 24-hour urinary hydroxyproline levels, on 4 occasions, plotted on centile charts for 24-hour urinary THP for normal girls. 10

\section{Results}

Fig. 1 shows THP levels for the scoliotic girls, plotted on normal centiles for THP. ${ }^{10}$ The different types of scoliosis are shown. The figures show the THP levels for each occasion that the tests were made. Results are not shown for 5 children who were outside the age range for the THP centiles.

Fig. 2 shows the standing heights, and Fig. 3 the sitting heights, of the same children; these measurements were taken at the same time as the urine samples were collected. The standing and sitting heights are plotted on centile charts for normal children. ${ }^{13}$ Tables 1 and 2 show the angulation of the curvature, THP levels, and the position of each child on the standing and sitting height centiles.

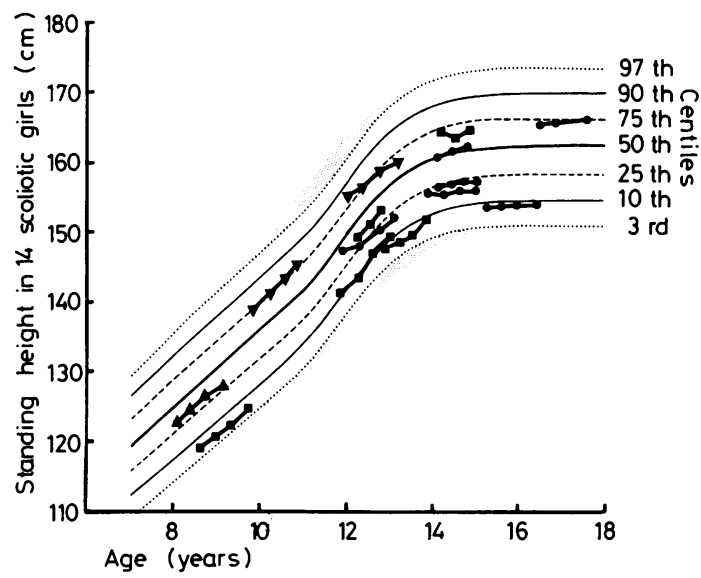

Fig. 2 Scoliotic girls: standing height measured on 4 occasions, plotted on centile charts for normal girls. ${ }^{13}$

Table 1 Details of the 14 scoliotic girls

\begin{tabular}{|c|c|c|c|c|c|c|c|c|c|}
\hline \multirow[t]{2}{*}{ Case } & \multirow{2}{*}{$\begin{array}{l}\text { Age } \\
\text { (years) }\end{array}$} & \multirow[t]{2}{*}{ Diagnosis } & \multirow{2}{*}{$\begin{array}{l}\text { Angulation of } \\
\text { spine at first visit }\end{array}$} & \multicolumn{2}{|l|}{ Centiles } & \multicolumn{4}{|c|}{ Total hydroxyproline $(\mathrm{mg} / 24 \mathrm{~h})$} \\
\hline & & & & Standing height & Sitting height & $1 s t$ & $2 n d$ & $3 r d$ & $4 t h$ \\
\hline 1 & 15 & AIS & $48^{\circ}$ & 3rd-10th & 10th & 16 & 14 & 16 & 20 \\
\hline 2 & 14 & AIS & $46^{\circ}$ & 25 th & 10th & 73 & 58 & 50 & 52 \\
\hline 3 & 17 & AIS & $52^{\circ}$ & $50-75$ th & 25-50th & 53 & 51 & 34 & 36 \\
\hline 4 & 14 & AIS & $58^{\circ}$ & 10th & 3rd & 37 & 40 & 28 & 37 \\
\hline 5 & 12 & AIS & $66^{\circ}$ & 25 th & 25 th & 105 & 85 & 116 & 128 \\
\hline 6 & 14 & AIS & $70^{\circ}$ & 50 th & 3rd & 102 & 93 & 59 & - \\
\hline 7 & 12 & JIS & $18^{\circ}$ & 10th & 3rd-10th & 87 & 82 & 87 & 96 \\
\hline 8 & 12 & JIS & $32^{\circ}$ & 25 th & 10th & 71 & - & 97 & 108 \\
\hline 9 & 9 & JIS & $44^{\circ}$ & 3rd & $<3$ rd & 42 & 48 & 54 & 65 \\
\hline 10 & 14 & JIS & $47^{\circ}$ & 50th & 25-50th & 42 & 30 & 30 & - \\
\hline 11 & 13 & JIS & $60^{\circ}$ & 10th & 3rd & 60 & 53 & 66 & 51 \\
\hline 12 & 8 & IIS & $56^{\circ}$ & $25-50$ th & 3rd-10th & 46 & 50 & 57 & 60 \\
\hline 13 & 10 & Cong & $25^{\circ}$ & 75th & 25-50th & 72 & 61 & 72 & 76 \\
\hline 14 & 12 & Cong & $30^{\circ}$ & 75th & $25-50$ th & 119 & 94 & 79 & 119 \\
\hline
\end{tabular}

AIS = adolescent idiopathic scoliosis, JIS = juvenile idiopathic scoliosis, IIS = infantile idiopathic scoliosis, Cong = congenital scolio sis. Conversion: traditional to SI units-THP: $1 \mathrm{mg} / 24 \mathrm{~h} \approx 0.00763 \mathrm{mmol} / 24 \mathrm{~h}$. 
Table 2 Details of the 7 scoliotic boys

\begin{tabular}{|c|c|c|c|c|c|c|c|c|c|}
\hline \multirow[t]{2}{*}{ Case } & \multirow{2}{*}{$\begin{array}{l}\text { Age } \\
\text { (years) }\end{array}$} & \multirow[t]{2}{*}{ Diagnosis } & \multirow{2}{*}{$\begin{array}{l}\text { Angulation of } \\
\text { spine at first visit }\end{array}$} & \multicolumn{2}{|l|}{ Centiles } & \multicolumn{4}{|c|}{ Total hydroxyproline $(\mathrm{mg} / 24 \mathrm{~h})$} \\
\hline & & & & Standing height & Sitting height & 1st & 2nd & $3 r d$ & 4 th \\
\hline 15 & 16 & AIS & $40^{\circ}$ & 10th & 3 rd & 88 & 114 & 117 & 134 \\
\hline 16 & 17 & AIS & $45^{\circ}$ & 50th & 25th & 136 & 106 & 124 & 102 \\
\hline 17 & 15 & AIS & $64^{\circ}$ & 25 th & 25 th & 98 & 93 & 66 & - \\
\hline 18 & 10 & JIS & $33^{\circ}$ & 50th & 25th & 75 & 85 & 106 & 130 \\
\hline 19 & 9 & JIS & $38^{\circ}$ & 75th & 75 th & 51 & - & 73 & 76 \\
\hline 20 & 10 & IIS & $45^{\circ}$ & $50-75$ th & 50th & 59 & - & 73 & 76 \\
\hline 21 & 9 & Cong & $61^{\circ}$ & $25-50$ th & $10-25$ th & 48 & - & 89 & - \\
\hline
\end{tabular}

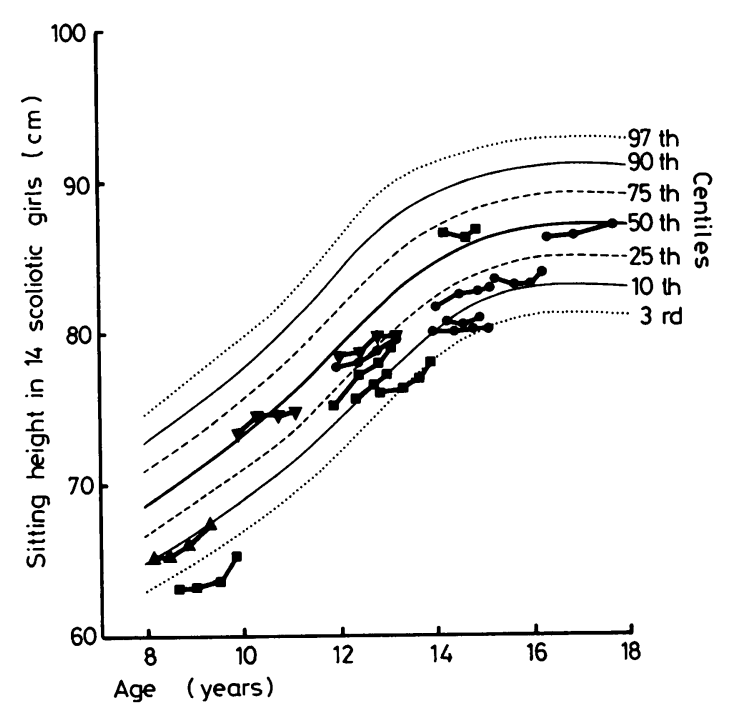

Fig. 3 Scoliotic girls: sitting height measured on 4 occasions, plotted on centile charts for normal girls. ${ }^{13}$

\section{Discussion}

THP levels were all within the normal range (Fig. 1. Tables 1 and 2). We were not able to find any difference in THP levels or body size between the different types of scoliosis (AIS, JIS, IIS, congenital), nor was there any difference in the degree of curvature in this small sample. In other studies THP levels have been found to be raised in scoliosis, ${ }^{14-15}$ but we did not find this was so. The reason for this might have been that the children were not undergoing any treatment except that a few were wearing Milwaukee braces. Spinal fusion, plasterof-Paris jackets, and spinal traction have been reported to increase the level of urinary THP excretion. ${ }^{14}$ In this study, we compared the THP results with THP centiles (constructed from longitudinal data obtained for normal children), ${ }^{10}$ and not with THP means for age from cross-sectional data, as in a previous study. ${ }^{14}$ Our results indicate that THP levels may be raised when a Milwaukee brace is worn, and that such levels decrease when the brace is removed. This cannot be substantiated in such a small group as other growth factors may be influencing the results.

The standing and sitting heights were within the normal range (Figs 2 and 3', but sitting heights for 12 of the girls (Fig. 3) were below the 50th centile. This reflects the shortening of the trunk due to spinal curvature. In 11 of these girls, regardless of the severity of the scoliosis, the sitting height was one centile below that of the standing height. In only one child was the sitting height on a higher centile than the standing height. These children were not short; their uncorrected standing height was normal but their sitting height reduced. Therefore, if their sitting height were corrected for the height loss due to the spinal curvature, their standing height would be greater than average. These findings are similar to those of others. ${ }^{3516}$

A correlation of $\mathrm{r}=0.65$ was found between THP and height velocity in the scoliotic girls. This correlation was higher in the normal children. ${ }^{10}$ It is possible that had an accurate method for estimating the 'true' height of a child with scoliosis been available and the numbers in this study been larger, the correlation between THP and height velocity might have been improved.

THP levels are related to growth in normal children, ${ }^{710}$ and they may therefore be a more accurate measurement of growth for scoliotic children than standing height and skeletal age. Skeletal age, if measured using the Tanner/Whitehouse Atlas, ${ }^{17}$ is retarded in children with IIS. ${ }^{18}$ Nordwall and Willner ${ }^{16}$ found that in early adolescence, skeletal development was advanced in girls with idiopathic scoliosis, and in late adolescence this tendency was reversed. One THP estimation (or preferably two), plotted on the centiles, will show whether a child is growing fast, or whether his growth rate is slowing down (Fig. 1). This knowledge may be valuable to orthopaedic surgeons in estimating the stage of development of their scoliotic patients.

We thank Mr C W Manning and his staff, Royal National Orthopaedic Hospital, for assistance, $\mathrm{Mr}$ 
R H Whitehouse, Institute of Child Health, for making the physical measurements, and Mrs Cynthia Isserlis for secretarial help.

Generous financial support was provided by the National Fund for Research into Crippling Diseases, the Sir Halley Stewart Trust Fund, and the Brompton Hospital Research Fund.

\section{References}

1 James J I P. Scoliosis. 2nd ed. Edinburgh: Livingstone, $1976 ; 38$.

2 Duthie R B. Significance of growth in orthopaedic surgery. Clin Orthop 1959; 14: 7-19.

3 Willner S. Growth in height of children with scoliosis. Acta Orthop Scand 1974; 45: 854-66.

4 Willner S. A study of growth in girls with adolescent idiopathic structural scoliosis. Clin Orthop 1974; 101: 129-35.

5 Burwell R G, Dangerfield P H, Vernon C L. Anthropometry and scoliosis. In: Zorab P A, ed. Scoliosis. London: Academic Press, 1977: 123-63.

6 Smiley J D, Ziff M. Urinary hydroxyproline excretion and growth. Physiol Rev 1964; 44: 30-44.

7 Zorab P A, Clark S, Harrison A, Seel J R. Hydroxyproline excretion and height velocity in normal adolescent boys. Arch Dis Child 1970; 45: 763-5.

8 Prockop D J, Kivirikko K I. Relationship of hydroxyproline excretion in urine to collagen metabolism. Ann Int Med 1967; 66: 1243-66.

- Jason H E, Fink C W, Wise W, Ziff M. Relationship between urinary hydroxyproline and growth. $J$ Clin Invest $1962 ; 41$ : 1928-35.
10 Clark S, Zorab P A. Hydroxyproline centiles for normal adolescent boys and girls. Clin Orthop 1978; 137: 217-26.

11 Manning C W. Surgical aspects. In: Zorab P A, ed. Scoliosis. London: Heinemann Medical, 1969: 1-29.

12 Clark S. Longitudinal growth studies in normal and scoliotic children. In: Zorab P A, ed. Scoliosis. London: Academic Press, 1977: 165-80.

13 Tanner J M, Whitehouse $R \mathbf{H}$. Clinical longitudinal standards for height, weight, height velocity, weight velocity, and stages of puberty. Arch Dis Child 1976; 51: 170-9.

14 Zorab, P A, Clark S, Cotrel Y, Harrison A. Bone collagen turnover in idiopathic scoliosis estimated from total hydroxyproline excretion. Arch Dis Child 1971; 46: 828-32.

15 Benson P. Letter: Hydroxyproline excretion in idiopathic, congenital, and paralytic scoliosis. Arch Dis Child 1972; 47: 476 .

16 Nordwall A, Willner S. A study of skeletal age and height in girls with idiopathic scoliosis. Clin Orthop 1975; 110: 6-10.

17 Tanner J M, Whitehouse R H, Marshall W A, Healey M J R, Goldstein H. Assessment of skeletal maturity and prediction of adult height (TW2 method). New York: Academic Press, 1975.

18 Krismundsdottir F, Jones P R M, Burwell R G, Jackson J P, Preston B J, Dangerfield P $\mathbf{H}$. The progress of skeletal maturation in patients with infantile idiopathic scoliosis (abstract). $J$ Anat 1978; $126: 435$.

Correspondence to Dr P A Zorab, Department of Paediatrics, Cardiothoracic Institute, Fulham Road, London SW3 6HP.

Received 5 June 1979 